\title{
High-Efficiency Violet-Emitting All-Inorganic Perovskite Nanocrystals Enabled by Alkaline-Earth Metal Passivation
}

Jia-Kai Chen,,${ }^{1, \dagger}$ Ju-Ping Ma, ${ }^{1, \dagger}$ Shao-Qiang Guo, ${ }^{2, \dagger}$ Ya-Meng Chen, ${ }^{1}$ Qing Zhao, ${ }^{3}$ Bin-Bin Zhang, ${ }^{1}$ Zhi-Yong Li, ${ }^{1}$ Yang Zhou, ${ }^{1}$ Jingshan Hou, ${ }^{4}$ Yoshihiro Kuroiwa, ${ }^{3}$ Chikako Moriyoshi, ${ }^{3}$ Osman M. Bakr, ${ }^{5}$ Junying Zhang, ${ }^{*, 2}$ and Hong-Tao Sun*,1,6

${ }^{1}$ College of Chemistry, Chemical Engineering and Materials Science, Soochow University, Jiangsu, 215123, China

${ }^{2}$ Department of Physics, Beihang University, Beijing, 100191, China

${ }^{3}$ Department of Physical Science, Hiroshima University, Higashihiroshima, Hiroshima 739-8526, Japan

${ }^{4}$ School of Materials Science and Engineering, Shanghai Institute of Technology, Shanghai, 201418, China

${ }^{5}$ Division of Physical Sciences and Engineering, King Abdullah University of Science and Technology (KAUST), Thuwal, 23955-6900, Saudi Arabia

${ }^{6}$ State Key Laboratory of Luminescence and Applications, Changchun Institute of Optics, Fine Mechanics and Physics, Chinese Academy of Sciences, Changchun, 130033, China 
Detailed method for the PLQY measurement: We used a comparative method to evaluate the PLQYs of our samples. ${ }^{1}$ The PLQY can be calculated using the slope of the line determined from the plot of the absorbance against the integrated fluorescence intensities, given by:

$$
Q=Q_{R}\left(\frac{\mathrm{m}}{m_{R}}\right)\left(\frac{n}{n_{R}}\right)^{2}
$$

in which $\mathrm{Q}$ is the value of PLQY, $\mathrm{m}$ is the slope of the line determined from the plot of the absorbance against the integrated fluorescence intensities, $\mathrm{n}$ is the refractive index of solvent and the subscript ${ }_{\mathrm{R}}$ refers to the reference sample. In this work, we used Rhodamine B as a reference sample which has a certain value of PLQY (65\%) in ethanol solvent at $25^{\circ} \mathrm{C} .{ }^{2}$ The refractive indexes of ethanol and n-hexane are 1.37 and 1.36 , respectively. ${ }^{3}$

For a typical sample of $10.5 \mathrm{~mol} \% \mathrm{Ca}^{2+}-\mathrm{CsPbCl}_{3} \mathrm{NCs}$, we detected four absorbance values and the corresponding integrated fluorescence intensities of this sample and Rhodamine B. The absorbances of the solutions of NCs and Rhodamine B were less than 0.08 to avoid the re-absorbance effect. All tests were conducted at $25^{\circ} \mathrm{C}$. The absorbances vs. the integrated fluorescence intensities obtained from the experiment and the resulting linear fits are shown in Figure S1. The fitted values of $\mathrm{m}$ and $m_{R}$ are $8.07053 \times 10^{7}$ and $9.43912 \times 10^{7}$, respectively. Then, the PLQY of this sample can be calculated as follows:

$$
Q=0.65 \times\left(\frac{9.43912 \times 10^{7}}{8.07053 \times 10^{7}}\right)\left(\frac{1.37}{1.36}\right)^{2} \times 100 \%=77.1 \%
$$



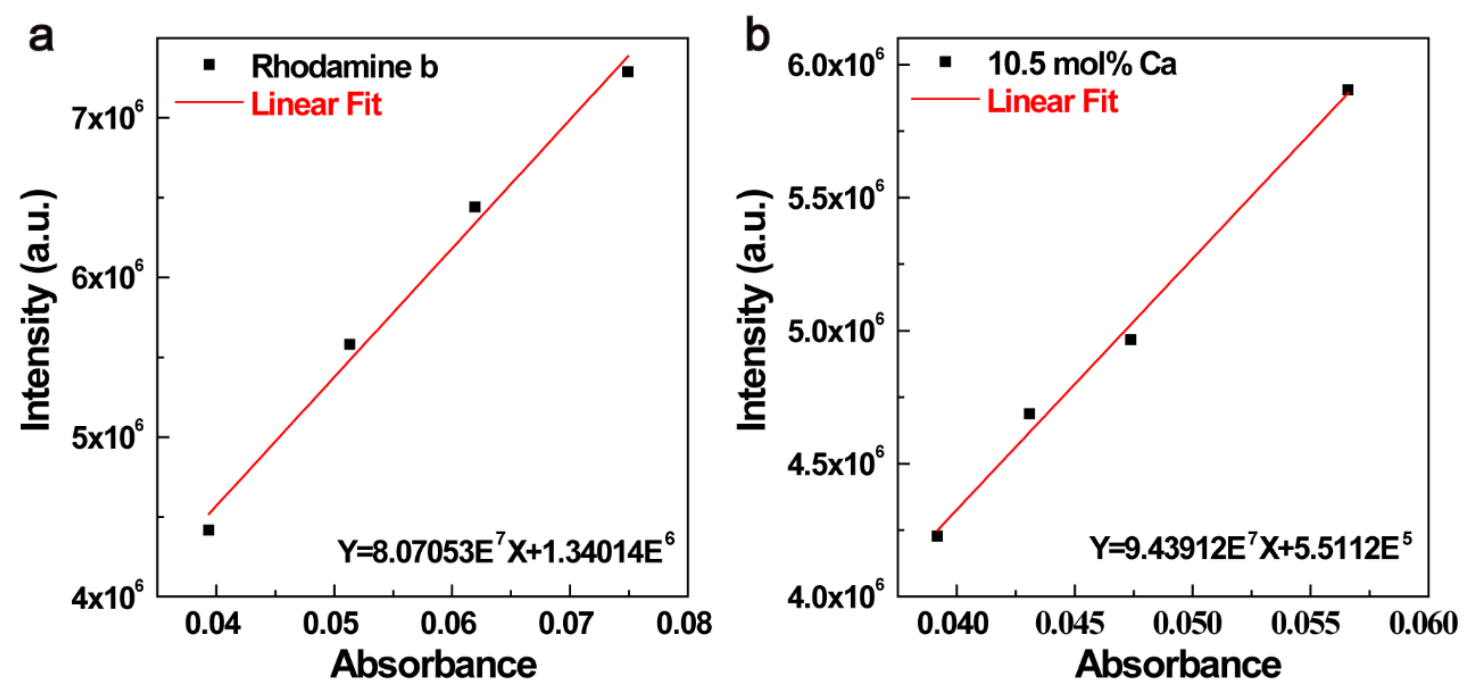

Figure S1. a-b) The graphs of absorbance vs. the integrated fluorescence intensities of $\mathrm{Rhb}(\mathrm{a})$ and $10.5 \mathrm{~mol} \% \mathrm{Ca}^{2+}-\mathrm{CsPbCl}_{3} \mathrm{NCs}(\mathrm{b})$.

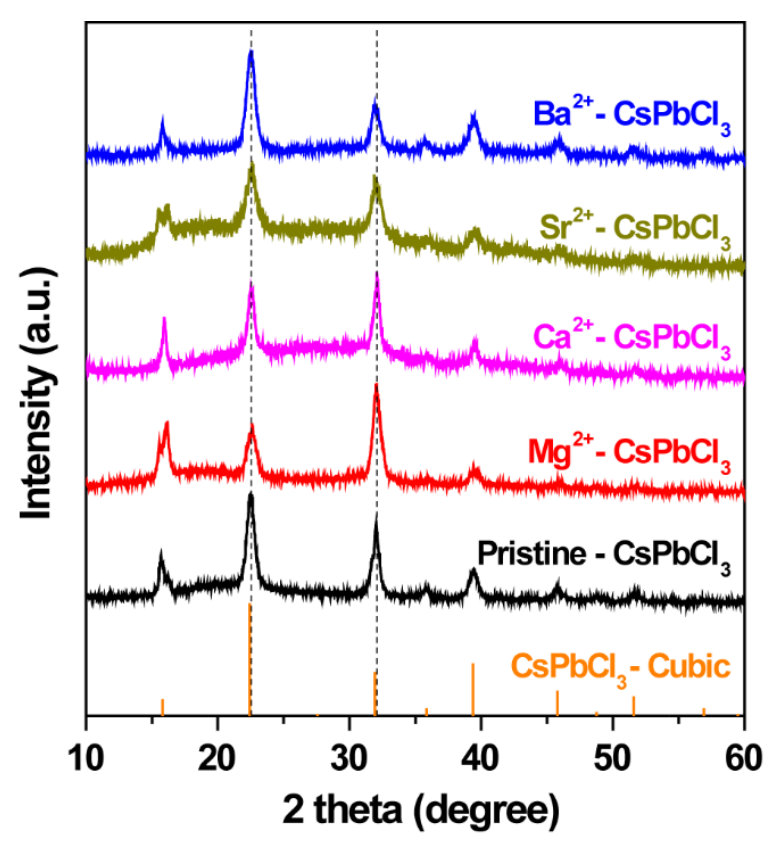

Figure S2. Laboratory XRD patterns of pristine and $\mathrm{AE}^{2+}-\mathrm{CsPbCl}_{3} \mathrm{NCs}$. The dotted vertical lines are drawn to guide the eye. 

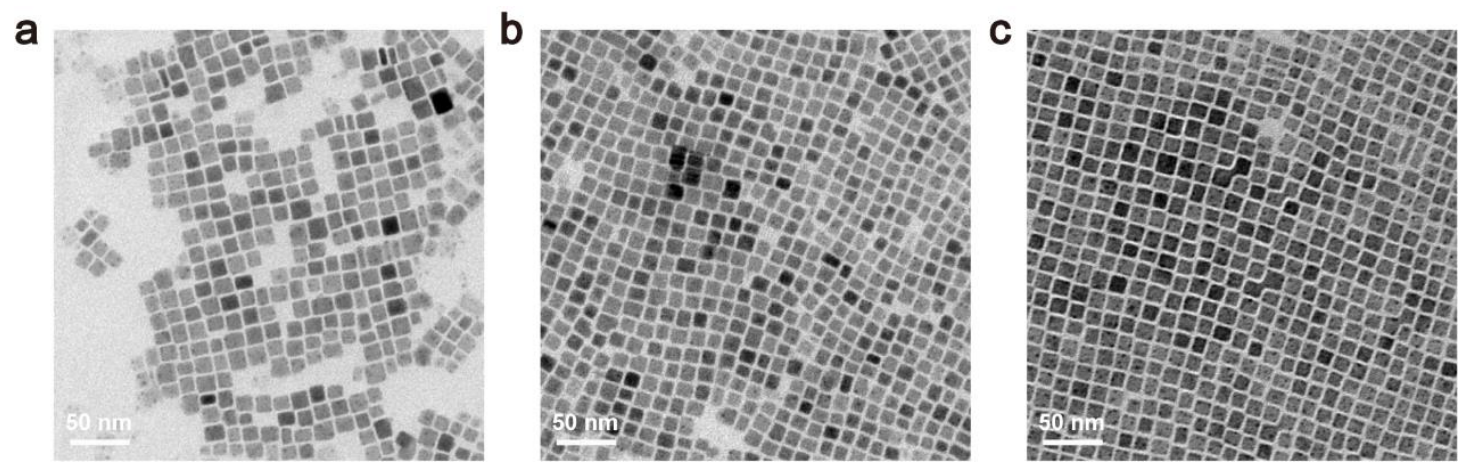

Figure S3. a-c) TEM images of $\mathrm{Mg}^{2+}-\mathrm{CsPbCl}_{3} \mathrm{NCs}(\mathrm{a}), \mathrm{Sr}^{2+}-\mathrm{CsPbCl}_{3} \mathrm{NCs}$ (b) and $\mathrm{Ba}^{2+}-\mathrm{CsPbCl}_{3} \mathrm{NCs}(\mathrm{c})$.
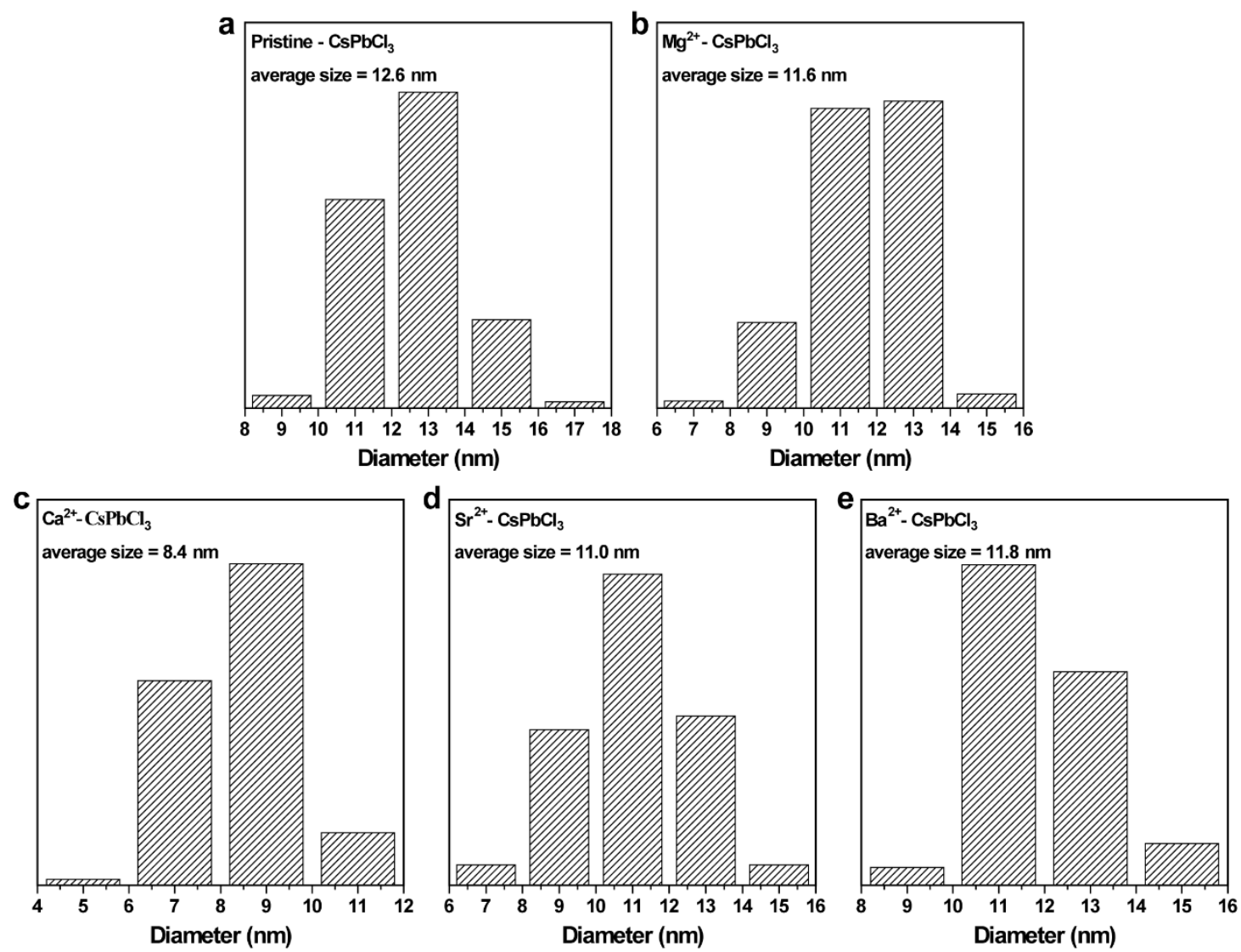

Figure S4. a-e) The size distribution histograms of pristine $\mathrm{CsPbCl}_{3} \mathrm{NCs}$ (a),
$\mathrm{Mg}^{2+}-\mathrm{CsPbCl}_{3} \quad \mathrm{NCs}$
(b), $\mathrm{Ca}^{2+}-\mathrm{CsPbCl}_{3} \quad \mathrm{NCs}$
(c), $\mathrm{Sr}^{2+}-\mathrm{CsPbl}_{3} \quad \mathrm{NCs}$
(d) and
$\mathrm{Ba}^{2+}-\mathrm{CsPbCl}_{3} \mathrm{NCs}(\mathrm{e})$. 


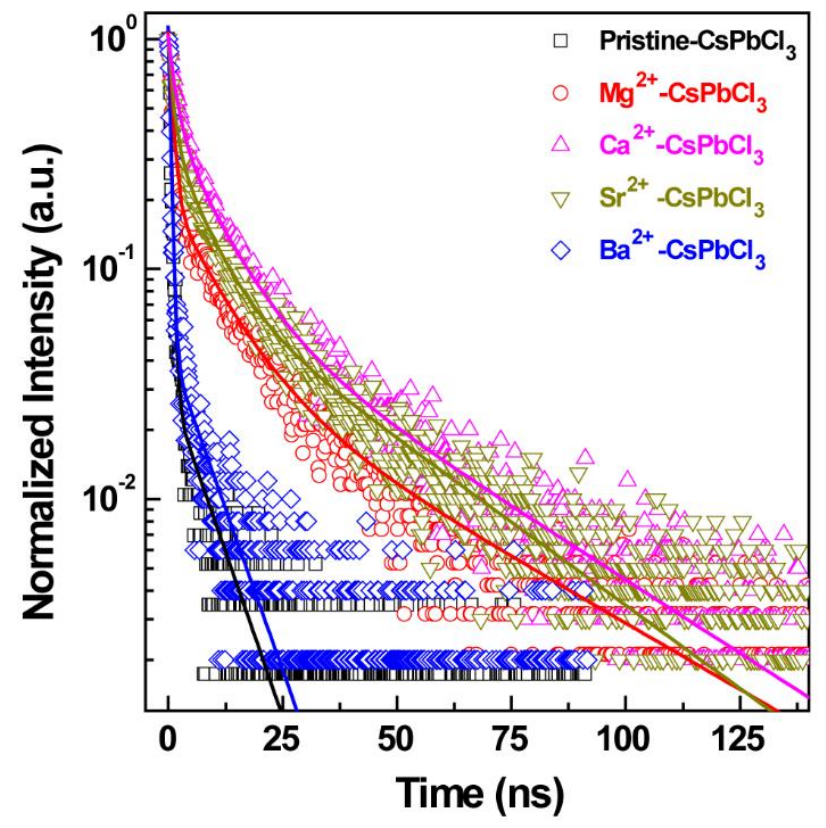

Figure S5. PL decay traces of pristine and $\mathrm{AE}^{2+}-\mathrm{CsPbCl}_{3} \mathrm{NCs}$.
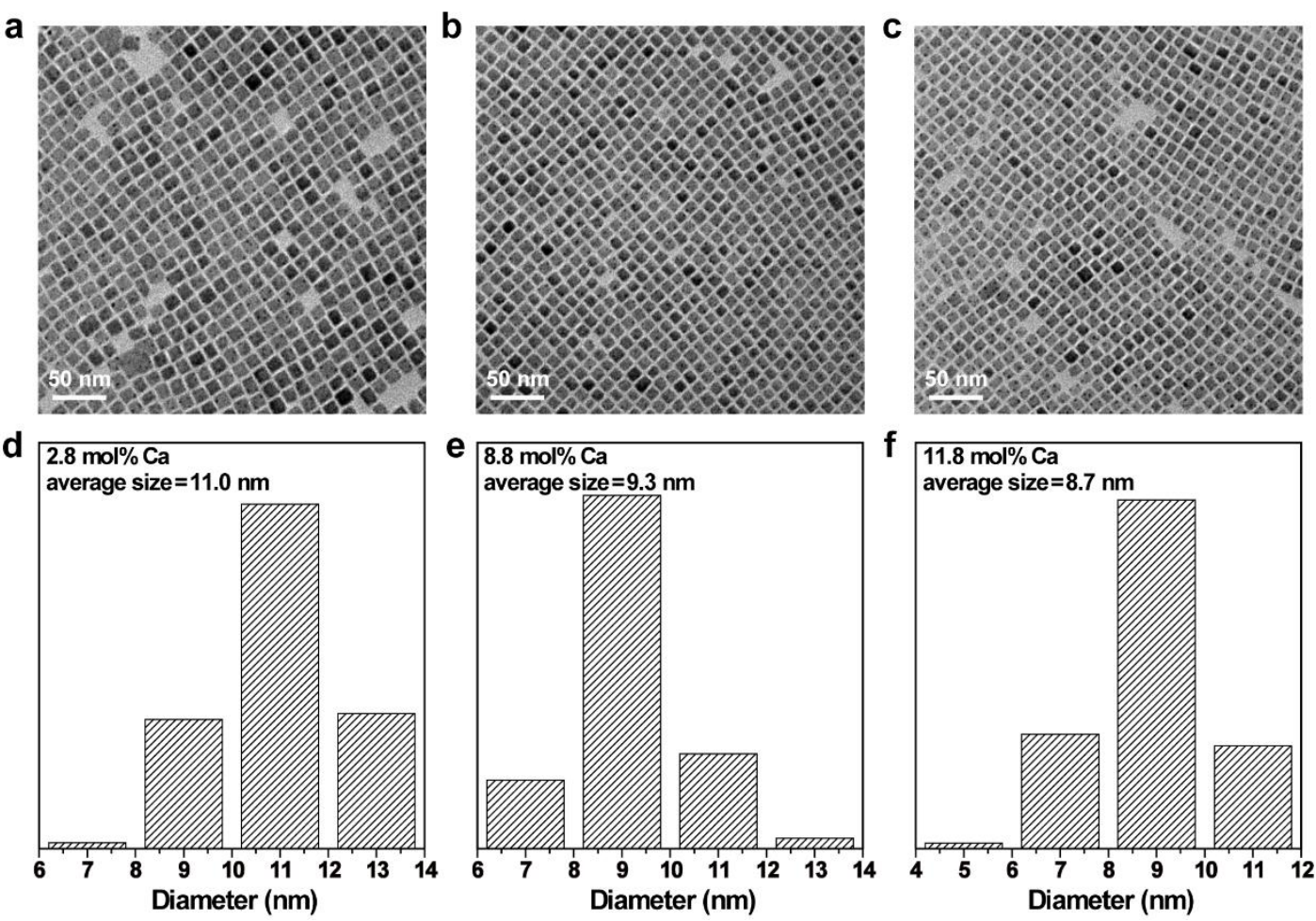

Figure S6. a-c) TEM images of $2.8 \mathrm{~mol} \%$ (a), $8.8 \mathrm{~mol} \%$ (b), $11.8 \mathrm{~mol} \%$ (c) $\mathrm{Ca}^{2+}-\mathrm{CsPbCl}_{3} \mathrm{NCs}$. d-f) The size distribution histograms of $2.8 \mathrm{~mol} \%$ (d), $8.8 \mathrm{~mol} \%$ (e), $11.8 \mathrm{~mol} \%$ (f) $\mathrm{Ca}^{2+}-\mathrm{CsPbCl}_{3} \mathrm{NCs}$. 


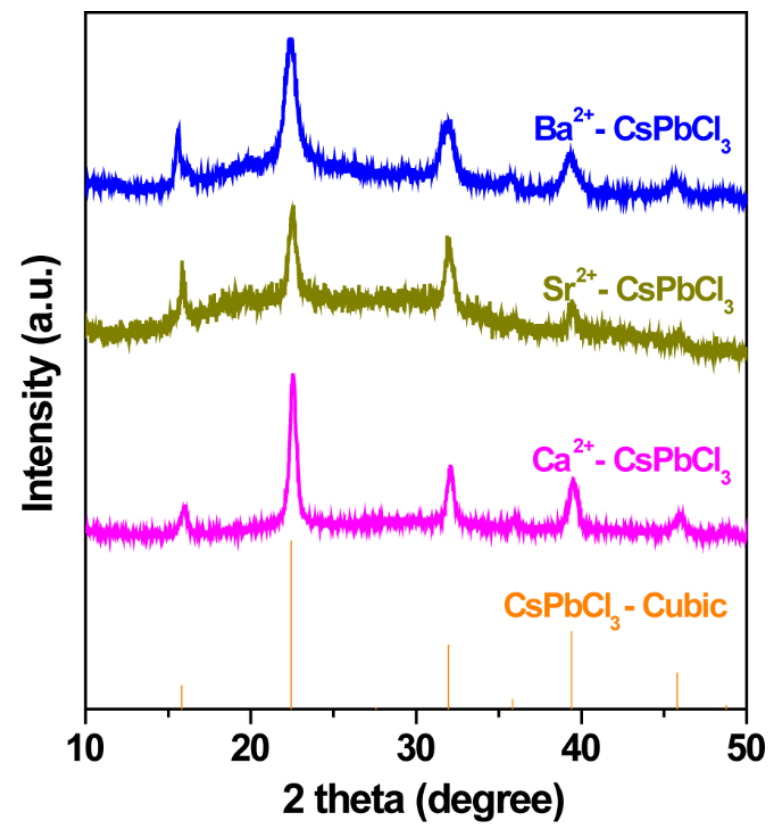

Figure S7. XRD patterns of $\mathrm{Ca}^{2+}-, \mathrm{Sr}^{2+}-$, and $\mathrm{Ba}^{2+}-\mathrm{CsPCl}_{3} \mathrm{NCs}$ after pyridine etching. To prepare the samples for the XRD measurements, the NC solution was evaporated under vacuum at room temperature and the precipitation was redispersed in toluene to form a concentrated $\mathrm{NC}$ solution. Then the concentrated solution was drop-cast onto a glass substrate for the XRD measurement. 

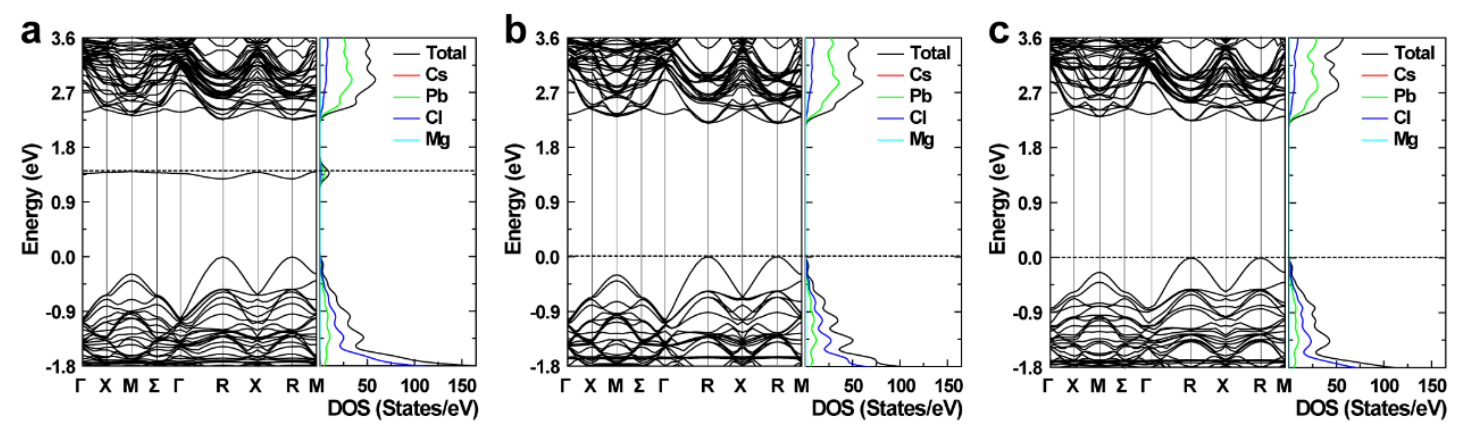

Figure S8. a) Band structure and $\mathrm{DOS}$ of $\mathrm{Mg}$-doped $\mathrm{CsPbCl}_{3}$ with a $\mathrm{Cl}$ vacancy. b) Band structure and DOS of $\mathrm{Mg}$-doped $\mathrm{CsPbCl}_{3}$ with a $\mathrm{Cs}$ vacancy. c) Band structure and DOS of $\mathrm{Mg}$-doped $\mathrm{CsPbCl}_{3}$ with a $\mathrm{Pb}$ vacancy. The dotted lines in $(\mathrm{a}, \mathrm{b}, \mathrm{c})$ represent the Fermi levels.
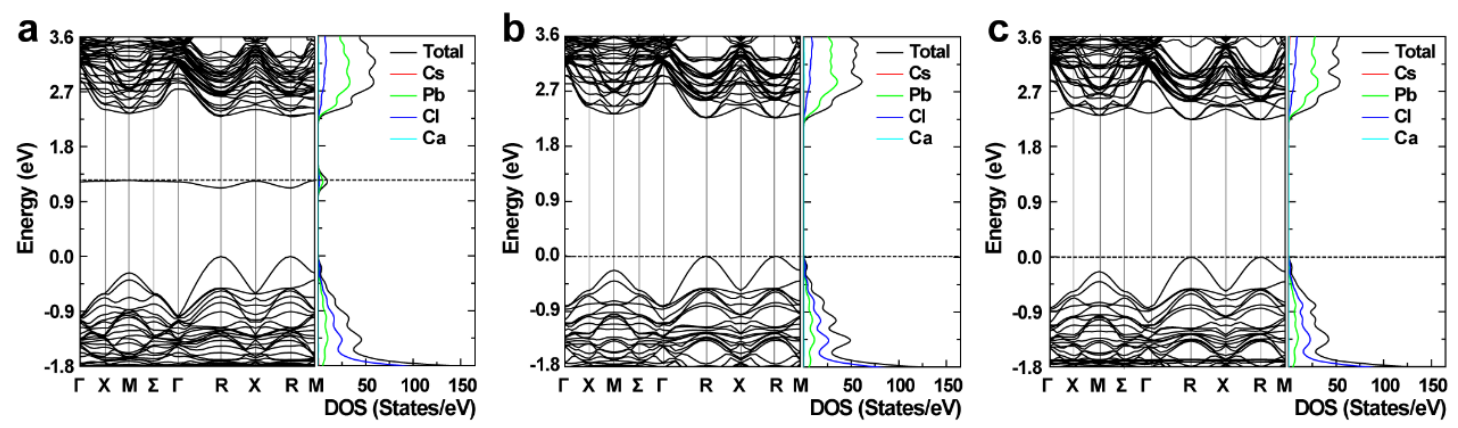

Figure S9. a) Band structure and $\mathrm{DOS}$ of $\mathrm{Ca}$-doped $\mathrm{CsPbl}_{3}$ with a $\mathrm{Cl}$ vacancy. b)

Band structure and DOS of Ca-doped $\mathrm{CsPbCl}_{3}$ with a Cs vacancy. c) Band structure and $\mathrm{DOS}$ of $\mathrm{Ca}$-doped $\mathrm{CsPbCl}_{3}$ with a $\mathrm{Pb}$ vacancy. The dotted lines in $(\mathrm{a}, \mathrm{b}, \mathrm{c})$ represent the Fermi levels. 

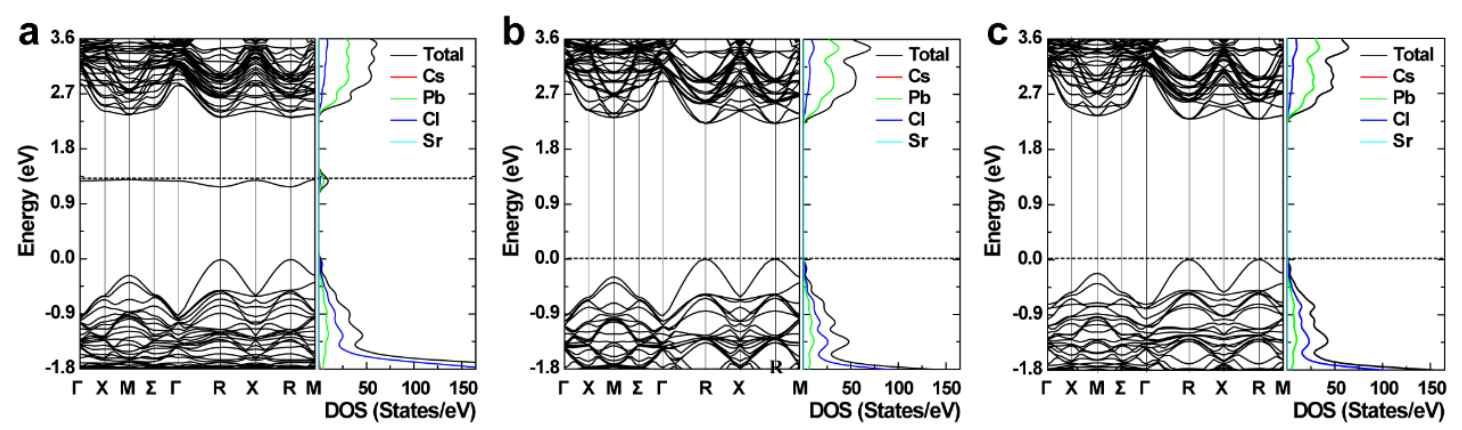

Figure S10. a) Band structure and $\mathrm{DOS}$ of $\mathrm{Sr}$-doped $\mathrm{CsPbl}_{3}$ with a $\mathrm{Cl}$ vacancy. b)

Band structure and DOS of Sr-doped $\mathrm{CsPCl}_{3}$ with a Cs vacancy. c) Band structure and DOS of Sr-doped $\mathrm{CsPbCl}_{3}$ with a $\mathrm{Pb}$ vacancy. The dotted lines in $(\mathrm{a}, \mathrm{b}, \mathrm{c})$ represent the Fermi levels.
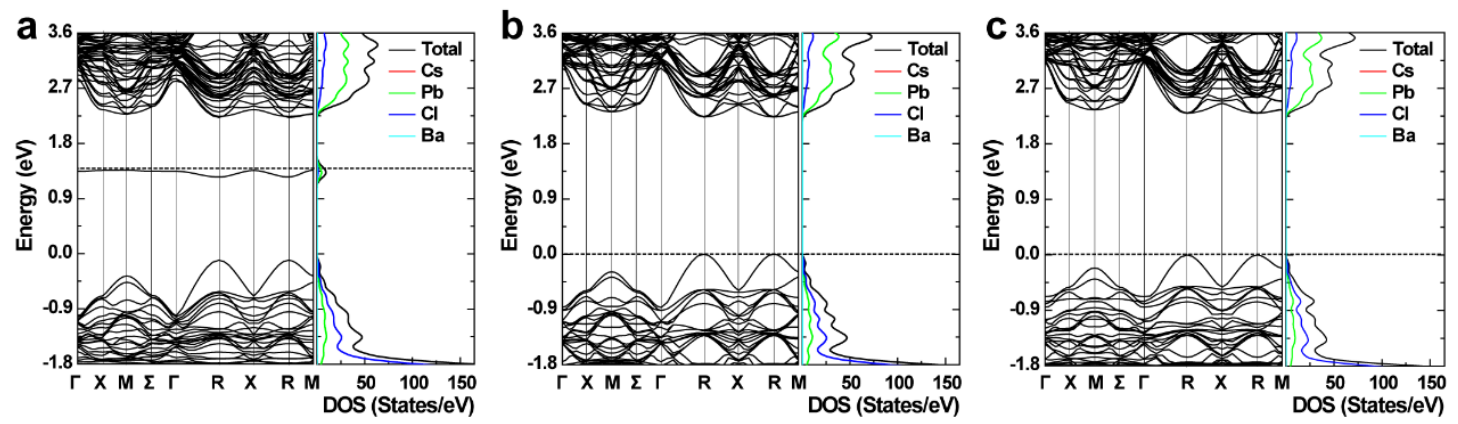

Figure S11. a) Band structure and $\mathrm{DOS}$ of $\mathrm{Ba}$-doped $\mathrm{CsPbCl}_{3}$ with a $\mathrm{Cl}$ vacancy. b)

Band structure and DOS of Ba-doped $\mathrm{CsPbCl}_{3}$ with a Cs vacancy. c) Band structure and $\mathrm{DOS}$ of $\mathrm{Ba}$-doped $\mathrm{CsPbCl}_{3}$ with a $\mathrm{Pb}$ vacancy. The dotted lines in $(\mathrm{a}, \mathrm{b}, \mathrm{c})$ represent the Fermi levels. 
Table S1. Fitted lifetimes monitored at $407 \mathrm{~nm}$, average lifetimes $\left(\boldsymbol{\tau}_{\mathbf{a v e}}\right)$, PLQY, radiative $\left(\Gamma_{\text {rad }}\right)$ and nonradiative $\left(\Gamma_{\text {non-rad }}\right)$ decay rates of pristine and $\mathrm{Ca}^{2+}-\mathrm{CsPCl}_{3}$ NCs.

\begin{tabular}{ccccccccccc}
\hline Sample & $\mathbf{A}_{\mathbf{1}}$ & $\begin{array}{c}\boldsymbol{\tau}_{\mathbf{1}} \\
(\mathbf{n s})\end{array}$ & $\mathbf{A}_{\mathbf{2}}$ & $\begin{array}{c}\boldsymbol{\tau}_{\mathbf{2}} \\
(\mathbf{n s})\end{array}$ & $\mathbf{A}_{\mathbf{3}}$ & $\begin{array}{c}\boldsymbol{\tau}_{3} \\
(\mathbf{n s})\end{array}$ & $\begin{array}{c}\boldsymbol{\tau}_{\text {ave }} \\
(\mathbf{n s})\end{array}$ & $\begin{array}{c}\text { PLQY } \\
(\mathbf{\%})\end{array}$ & $\begin{array}{c}\Gamma_{\text {rad }} \\
\left(\mu \mathbf{s}^{-1}\right)\end{array}$ & $\begin{array}{c}\Gamma_{\text {non-rad }} \\
\left(\mu \mathbf{s}^{-1}\right)\end{array}$ \\
\hline pristine & 0.55 & 0.49 & 0.55 & 0.49 & 0.03 & 7.57 & 2.59 & 0.8 & 3.08 & 383.01 \\
$\mathbf{2 . 8} \mathbf{~ m o l \%}$ & 0.46 & 0.71 & 0.66 & 0.71 & 0.04 & 17.79 & 8.78 & 8.6 & 9.79 & 104.10 \\
$\mathbf{8 . 8} \mathbf{~ m o l \%}$ & 0.68 & 0.83 & 0.31 & 4.56 & 0.06 & 20.98 & 10.30 & 24.7 & 23.98 & 73.11 \\
$\mathbf{1 0 . 5} \mathbf{~ m o l \%}$ & 0.57 & 1.55 & 0.37 & 8.62 & 0.08 & 34.00 & 17.86 & 77.1 & 43.17 & 12.82 \\
$\mathbf{1 1 . 8} \mathbf{~ m o l \%}$ & 0.58 & 1.73 & 0.44 & 8.32 & 0.05 & 37.96 & 15.89 & 73.2 & 46.07 & 16.87 \\
\hline
\end{tabular}

Table S2. Ionic radii of six-coordinate $\mathrm{AE}$ and $\mathrm{Pb}$ ions and their bond dissociation energies of metal chloride.

\begin{tabular}{cccccc}
\hline Different ions & $\mathbf{M g}^{2+}$ & $\mathbf{C a}^{2+}$ & $\mathbf{S r}^{2+}$ & $\mathbf{B a}^{2+}$ & $\mathbf{P b}^{2+}$ \\
\hline $\begin{array}{c}\text { Radius of ion }(\AA)^{4} \\
\text { Bond dissociation energies } \\
\text { of metal chloride }(\mathbf{K J}\end{array}$ & 0.72 & 1 & 1.18 & 1.35 & 1.19 \\
\begin{tabular}{c}
$\left.\mathbf{m o l}^{-\mathbf{1}}\right)^{\mathbf{5}}$ \\
\hline
\end{tabular} & 312 & $409 \pm 8.7$ & 409 & 443 & $301 \pm 50$ \\
\hline
\end{tabular}




\section{REFERENCES}

(1) Wei, H. B.; Zhao, Z. F.; Wei, C.; Yu, G.; Liu, Z. W.; Zhang, B.; Bian, J.; Bian, Z. Q.; Huang, C. H. Antiphotobleaching: a type of structurally rigid chromophore ready for constructing highly luminescent and highly photostable europium complexes. Adv. Funct. Mater. 2016, 26, 2085-2096.

(2) Kubin, R. F.; Fletcher, A. N. Fluorescence quantum yields of some rhodamine dyes. $J$. Lumin. 1982, 27, 455-462.

(3) Orge, B.; Iglesias, M.; Rodriguez, A.; Canosa, J. M.; Tojo, J. Mixing properties of (methanol, ethanol, or 1-propanol) with (n-pentane, n-hexane, n-heptane and n-octane) at 298.15 K. Fluid Phase Equilib. 1997, 133, 213-227.

(4) Shannon, R. D. Revised effective ionic-radii and systematic studies of interatomic distances in halides and chalcogenides. Acta Crystallogr., Sect. A: Cryst. Phys., Diffr., Theor. Gen. Crystallogr. 1976, 32, 751-767.

(5) Luo, Y.-R.; Kerr, J. A. Bond dissociation energies. CRC Handbook of Chemistry and Physics, Vol. 87; CRC Press: Boca Raton, FL, USA, 2007. 